\title{
Broadband over Power Line (BPL): An Emerging Technology for Bangladesh
}

\author{
Md. Belayat Hossain1*, Mir Toufikur Rahman², Omar Asif33, Md. Ashfaqur Rahman", \\ Muhammad E. H. Chowdhury ${ }^{5}$ \\ ${ }^{1}$ Department of ETE, Atish Dipankar University of Science \& Technology, Dhaka, Bangladesh \\ ${ }^{2}$ Department of EEE, University of Asia Pacific, Dhaka, Bangladesh \\ ${ }^{3}$ Department of EEE, Atish Dipankar University of Science \& Technology, Dhaka, Bangladesh \\ ${ }^{4}$ Department of ETE, University of Liberal Arts Bangladesh, Dhaka, Bangladesh \\ ${ }^{5}$ Department of APECE, University of Dhaka, Dhaka, Bangladesh \\ Email: ${ }^{\text {enamul@univdhaka.edu }}$
}

Received 20 January 2014; revised 20 February 2014; accepted 20 March 2014

Copyright (C) 2014 by authors and Scientific Research Publishing Inc.

This work is licensed under the Creative Commons Attribution International License (CC BY).

http://creativecommons.org/licenses/by/4.0/

(c) (i) Open Access

\begin{abstract}
Broadband over Power Line (BPL) is an alternative means of providing high-speed Internet access, Voice over Internet Protocol (VoIP), and other broadband services to homes and businesses by using the existing medium voltage (MV) and low voltage (LV) power lines. This paper provides a comprehensive understanding about BPL with its implementation prospects. In this context, the existing power grid infrastructures are discussed elaborately. BPL system functionality with its components and its benefits over other access technologies is also pointed out. Implementation scenarios for various deployment options are illustrated here. The different implementation challenges for BPL system, such as the characteristics of power lines, attenuation problem, noise, potential interference with the other radio frequencies are also presented with their remedies. Comparative analysis between several broadband access technologies shows the feasibility of BPL deployments all over the world.
\end{abstract}

\section{Keywords}

Broadband over Power Line, Orthogonal Frequency Division Multiplexing, Power Grid, Access BPL, In-House BPL, Broadband Access Technologies

\section{Introduction}

There are two basic means of providing communications services: wireless or wireline. On the wireline side,

*Corresponding author.

How to cite this paper: Hossain, M.B., Rahman, M.T., Asif, O., Rahman, M.A. and Chowdhury, M.E.H. (2014) Broadband over Power Line (BPL): An Emerging Technology for Bangladesh. Int. J. Communications, Network and System Sciences, 7, 346-354. http://dx.doi.org/10.4236/ijcns.2014.79036 
there are currently three means of providing broadband services: digital subscriber line (DSL) through telephone company telephone lines, cable modem through cable company coaxial cable lines, and fibre to the X (FTTX) through optical fibre lines to home or business to deliver broadband services. With the advent of broadband over power lines (BPL), a fourth wired option is emerging that uses electric utility power lines. Power lines are attractive for communications purposes because they have an omnipresence that reaches most homes and businesses, even in the most rural areas. This ubiquity implies a possible reduction in both time and cost for broadband deployment. In this sense, power lines, like Radio Frequency (RF) spectrum, can be considered a very valuable national resource, or even a national treasure. And of course, there is the inside-home power line wiring that can literally turn every outlet plug into a broadband communications access port. BPL is still a new technology in the communication fields by which broadband services can be provided throughout the country, as the power line network is thought to be ubiquitous. In Bangladesh, especially the rural areas, where broadband services are still not available will have a chance to access broadband services through the BPL technology. The objective of this paper is to provide a comprehensive knowledge about broadband over power line and also to present implementation scenarios, challenges and implementation prospects over other technologies.

\section{BPL Overview}

Broadband over power line or BPL theoretically has the ability to enable data to be transmitted over power lines into homes and offices at data rates between 500 kilo bits per second (kbps) and 3 mega bits per second (Mbps), which is equivalent to most DSL and cable modem transmission rates [1]. So, BPL provides an emerging alternative to conventional methods of obtaining high-speed Internet access. The key reason for the excitement concerning BPL technology is the fact that virtually every home and office is connected to a power grid and contains electrical wiring. Thus, any mechanism that provides the potential to transmit high-speed data over existing electrical wiring has the potential to provide a truly pervasive method to access the Internet.

\section{Overview of Grid Structure and Topology}

A power grid basically consists of power plants or generators, transmission substations, transmission lines, power substations with transformers to change voltage levels, and distribution lines that collectively generate and carry the electricity from power plants all the way to wall plugs (Figure 1).

Power plants are basically spinning electricity generators. Spinning can be performed by a steam turbine, and steam can be created by burning fossil fuel or from a nuclear reactor. A generator's output is three-phase alternating current (AC) power at voltage levels in the thousands. The three single phases are synchronized and offset by 120 degrees. Power $P$, transferred over lines and delivered to customers, is equal to the product of voltage

$V$ and current $I(P=I V)$. Power loss in the line grows with the square of the current, that is, $P_{\text {loss }}=R_{\text {line }} \times I^{2}$, where $R_{\text {line }}$ is the line resistance and depends on the line material and increases with the length of the line. For a

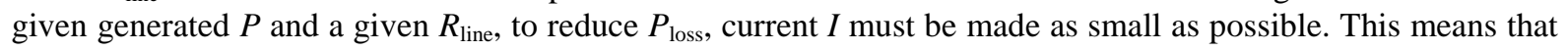
the line voltage must be made as large as possible, especially for long-distance transmissions.

Transmission substations located next to power plants use large transformers to step up generator output from thousands of volts to hundreds of thousands of volts (typically between 155,000 and 765,000 volts), thus allowing megawatts of power transmission over distances of 300 miles or more [2].

At power substations, voltages are stepped down and lines are branched out to cover larger areas. This is performed successively, transforming and branching out from extremely high voltage (EHV, typically 155 to 765 kilo volts or $\mathrm{kV}$ ) to high voltage (HV, typically 45 to $155 \mathrm{kV}$ ), and then from $\mathrm{HV}$ to medium voltage (MV, typically 2 to $45 \mathrm{kV}$ ), and finally from MV to low voltage (LV, typically 100 to $600 \mathrm{~V}$ ) for delivery to homes or businesses. The result is a tree-structured power distribution hierarchy. Basically, EHV and HV are used to transmit AC electric power, and MV and LV are used to distribute it (Figure 2).

\section{BPL System Functionality}

There are two predominant types of BPL communications configurations: Access BPL and In-House BPL. Access BPL is comprised of injectors (used to inject High Frequency signals onto medium or low voltage power lines), extractors (used to retrieve these signals) and repeaters (used to regenerate signals to prevent attenuation losses). In addition to taking advantage of the power line infrastructure, In-House BPL modems utilize the existing house wiring to provision a Local Area Network (LAN) that can be used throughout the home [3]. 


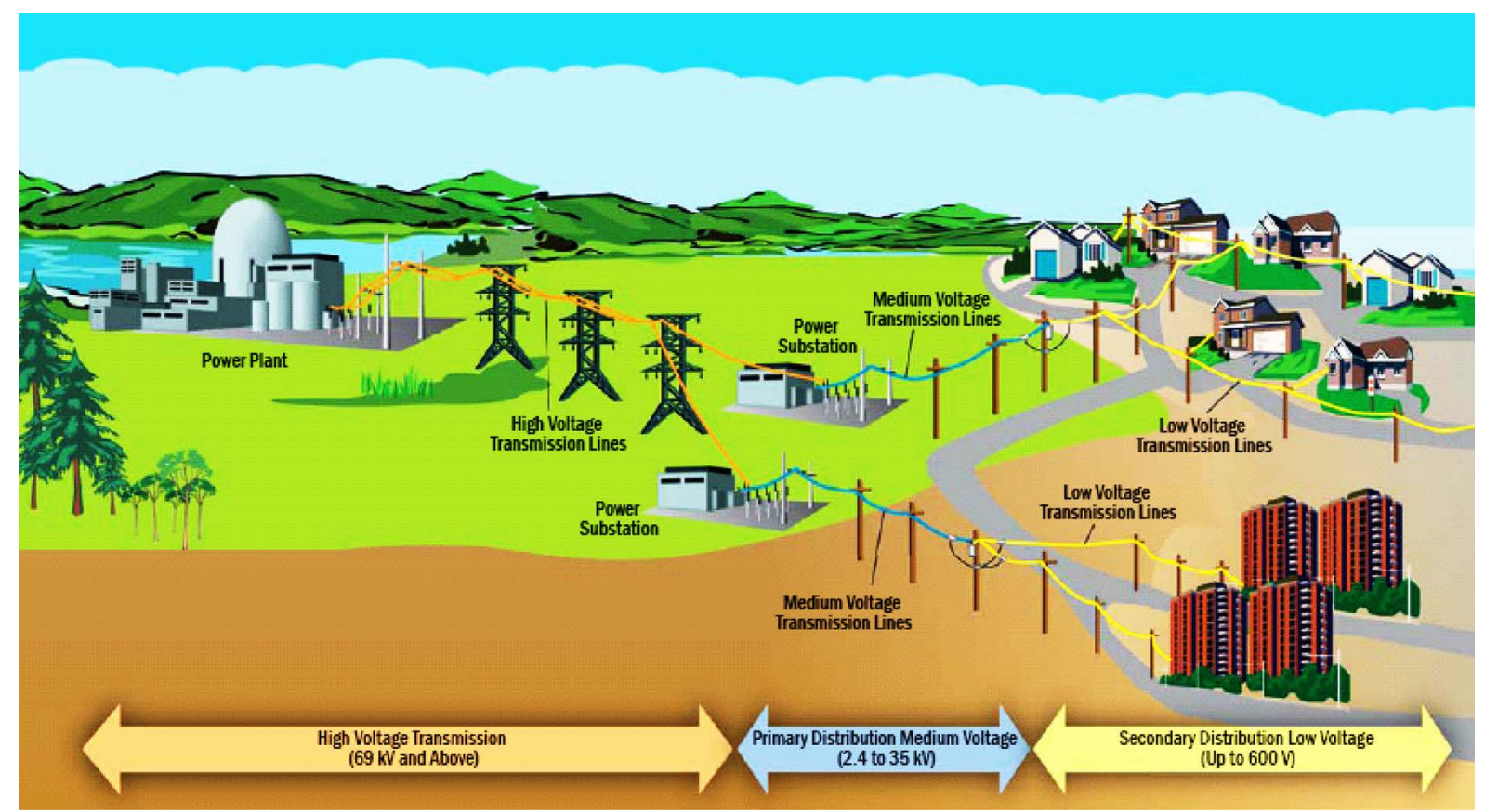

Figure 1. Typical electric power grid.

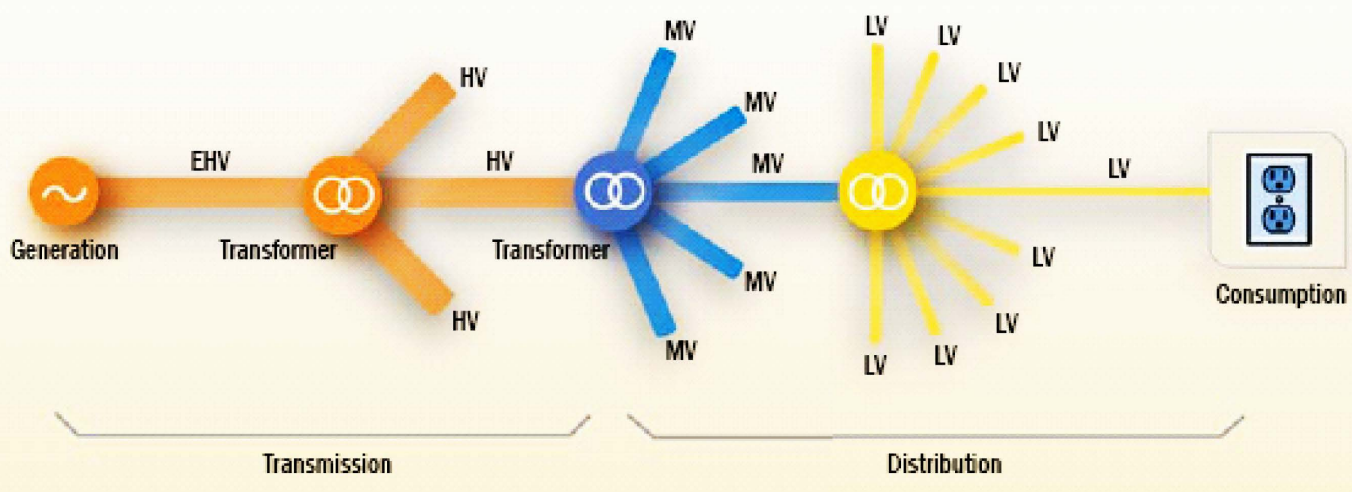

Figure 2. From generation to consumption: power grid hierarchies.

There are several different approaches to overcome the hurdles presented when transmitting data through power lines. When power leaves the power plant, it hits a transmission substation and is then distributed to high voltage transmission lines. When transmitting broadband, these high-voltage lines represent the first hurdle. The power flowing down high-voltage lines is between 155,000 to 765,000 volts. That amount of power is unsuitable for data transmission. It's too noisy. Both electricity and radio frequency (RF) are used to transmit data vibrating at certain frequencies. To transmit data cleanly from point to point; it must have a dedicated band of the radio spectrum to vibrate without interference. Hundreds of thousands of volts of electricity don't vibrate at a consistent frequency. That amount of power jumps all over the spectrum. As it spikes and hums along, it creates all kinds of interference. If it produces a spike at a certain frequency that is used for radio frequency data transmission, then it will cancel out that signal and the data transmission will be dropped or damaged on route [4]. (Figure 3).

BPL bypasses this problem by avoiding high-voltage power lines all together. The system drops the data off of traditional fibre-optic lines downstream, onto the much more manageable 7200 volts of medium-voltage 


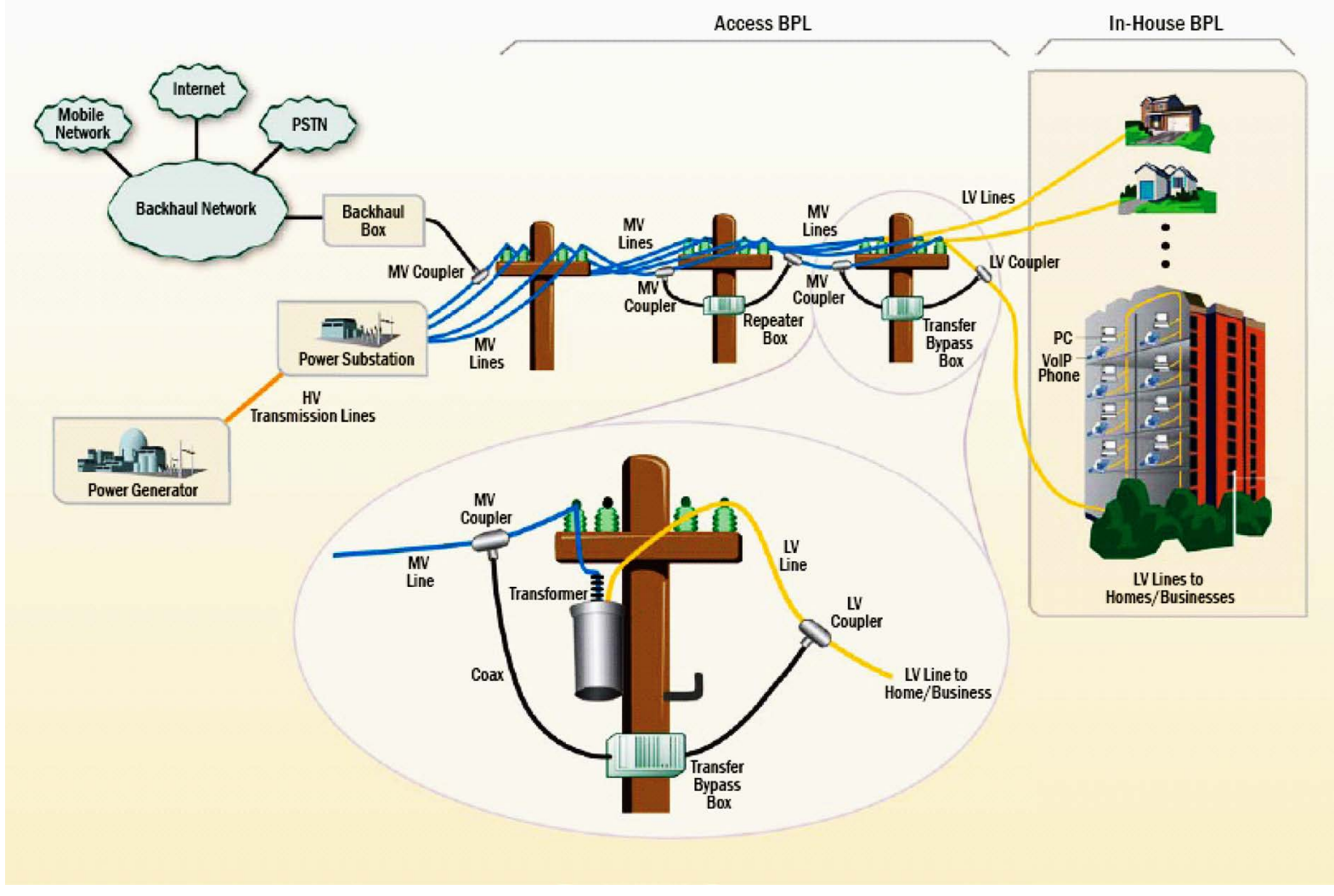

Figure 3. An overview of the BPL system [2].

power lines through injector/concentrator. Inside the injector, there are transmitter and receiver sections as well as a signal converter. The transmitter and receiver operate on different frequencies, which in effect enable full duplex transmission over the power line. The injector converts the signal on the fibre or metallic $\mathrm{T}_{1}$ line into the signal format used for transmission over the medium-voltage power line. Once dropped onto the medium-voltage lines, the data can only travel so far before it degrades. To counter this, special devices are installed on the lines to act as repeaters. The repeaters take in the data and repeat it in a new transmission, amplifying it for the next leg of the journey. The BPL repeater is installed approximately every 1000 to $2500 \mathrm{ft}$. along the mediumvoltage power line. The coupler allows the data on the line to bypass transformers, and the bridge, a device that facilitates carrying the signal into the homes.

The transformer's job is to reduce the 7200 volts down to the 220 volt standard that makes up normal household electrical service. There is no way for low-power data signals to pass through a transformer, so a coupler is needed to provide a data path around the transformer. With the coupler, data can move easily from the MV line to the LV line and into the house without any degradation. The last mile is the final step that carries data into the subscriber's home or office. In the various approaches to last-mile solutions for BPL, some companies carry the signal in with the electricity on the power line, while others put wireless links on the poles and send the data wirelessly into homes. The Bridge facilitates both. The bridge mounted on a utility pole containing a transformer may also include one or more communications functions such as: data routing, managing subscriber information, Dynamic Host Configuration Protocol (DHCP), assignment of Internet Protocol (IP) addresses, encryption, symmetric data transmission to all electrical outlets in subscriber home or office. The signal can be received by a powerline modem that plugs into the wall. Inductive couplers are also used to connect BPL modems to the medium voltage power lines to extract information signal. The modem sends the signal to the computer. BPL modems use silicon chipsets specially designed to handle the work load of pulling data out of an electric current. Using specially developed modulation techniques and adaptive algorithms, BPL modems are capable of handling powerline noise on a wide spectrum [4].

From the end user's perspective, BPL technology works by sending high-speed data along medium or low 
voltage power lines into the customer's home. The signal traverses the network over medium and low voltage lines either through the transformers or by-passes the transformer using bridges or couplers. The technology transports data, voice and video at broadband speeds to the end-user's connection. The user only needs to plug an electrical cord from the BPL modem into any electrical outlet then plug an Ethernet or universal serial bus (USB) cable into the Ethernet card or USB interface on their PC. Any Internet Service Provider (ISP) can interface with the BPL network and provide high speed Internet access. The data signal can also interconnect with wireless, fibre or other media for backhaul and last mile completion.

\section{Different Deployment Options}

The MV and LV line portions of the BPL are usually referred to as the access BPL, while the portion inside a home or office using the inside wiring is called the in-house BPL. BPL can be deployed either as end-to-end BPL or as hybrid BPL, using one of the three options illustrated in Figure 4 [2].

An end-to-end BPL system uses both access BPL and in-house BPL, i.e., power lines are used all the way from the power substation to the end user. Two of the three BPL deployment options involve the access BPL portion of an end-to-end system, and then the BPL signal can either (1) bypass the MV/LV transformer or (2) go through the transformer. For these two options, bypass boxes and LV couplers must be installed on all LV lines, and in-house BPL modems are required.

The third BPL deployment option is hybrid BPL. In this option, typically only the MV lines are used, and a fixed wireless network replaces the LV lines and in-house BPL. In hybrid BPL, the bypass box does not couple the broadband signal to/from the LV line but converts it to/from a wireless format and delivers it to the wireless access point (AP) also located on the pole. For hybrid BPL, bypass boxes with wireless conversion boards, wireless APs, and existing standard wireless user modems are required.

\section{Transmission Methods}

BPL field trials resulted in the use of two transmission methods to convey information over power lines. One method is referred to as orthogonal frequency division multiplexing (OFDM) and other method is referred to as direct sequence spread spectrum (DSSS).

\subsection{Benefits of the BPL over Other Access Methods}

\subsubsection{Benefits for Service Providers}

A major advantage for the utility companies is that most of the infrastructure is already in place because the

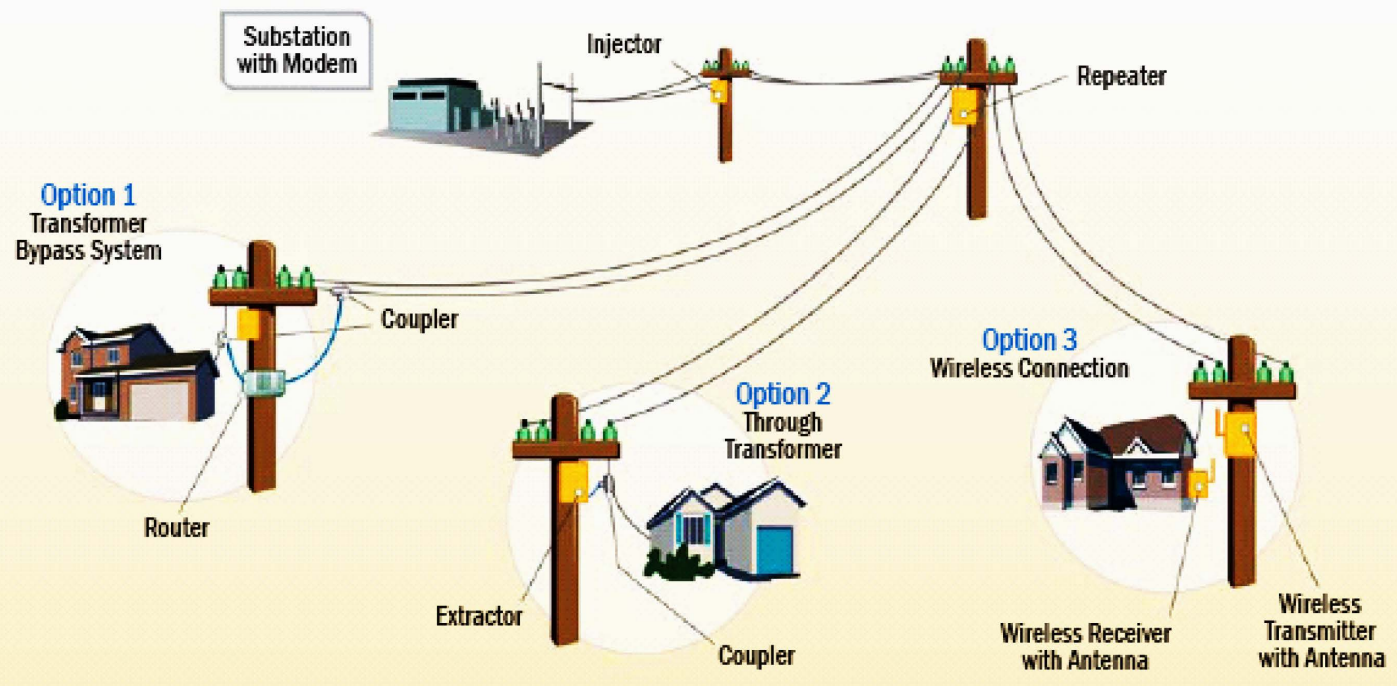

Figure 4. BPL deployment options. 
technology relies on the existing power grid. This enhances the cost-effectiveness of rolling out power line communications. Only the substation server equipment and customer conditioning service units need to be installed in order to establish a digital power line network [5].

Another important aspect to consider for providers is that of coverage; the power grid is everywhere. The low voltage power grid has a unique feature; it is comprised of an already existing networked infrastructure to billions of private customers as well as businesses. The power grid has the greatest availability of any other solution that exists today.

\subsubsection{Benefits for the End Users}

The equipment needed to set up BPL in home is cheaper on average than that of other broadband solutions such as DSL and cable modem. The equipment uses existing power outlets in the home making it a lot easier to set up and is very simple as it is plug and play. There is no need for complicated wiring and additional installations; and it is possible to move computers and appliances anywhere. The uplink and downlink speeds are similar. This is especially important for the uplink as the speed is higher than the DSL and Cable. For users in rural areas who cannot receive DSL or cable modem services, BPL can provide an all-in-one service-telephone, cable television, and high-speed data.

\section{Implementation Challenges}

Power lines were not designed for data transmission; they were created to deliver power at 50 to $60 \mathrm{hertz}(\mathrm{Hz})$. Broadband data are transmitted at different frequencies, so the data and electricity can travel in the same wire; however, several obstacles have to be overcome to enable high-speed and long-distance transmission of data on powerlines [6].

\subsection{The Nature of the Power Grid}

The most obvious challenge to implement BPL arise from the fact that power line grids were originally developed to transmit electrical power from a small number of sources (the generators) to a large number of sinks (the end customers). Power grids were neither designed nor devised for communications purposes. The main challenges to BPL are the extremely harsh \& unpredictable nature of power grid and the time-and-location-variable characteristics of the power line channel, and potential interference arising from the power grid [2]. Because power lines are not twisted and have no shielding, they can produce electromagnetic radiation that is easily detected by radio receivers. For the same reasons, power lines can also easily pick up nearby radio frequency signals. Thus, addressing mutual interference is not only a challenge, but becomes a valid regulatory concern.

\subsection{Power Line Noise}

The power line noise is typically time, location, and frequency dependent. Time-variable behaviour is mainly due to the dynamically changing nature of the load connected to the power lines. Line branching, the number and types of branches, the lengths of line segments, the types of power line equipment connected (such as capacitor banks and transformers), and the kind of loads connected, all affect power line characteristics.

\subsection{Channel Attenuation}

Attenuation or reduction of signal strength occurs either on longer lengths of distribution feeders, or when a given feeder changes configuration several times such as from overhead to underground or from cross arm to a more compact configuration. Attenuation must be overcome to enable long-distance data transmission. Higher frequency data signals are typically attenuated much more seriously than lower frequency signals. Signals lose energy as they propagate for several reasons including the change in impedance on the line at every connection, splice, taps, standoff or even a location where the line is close to something else.

\subsection{Attenuation Problems at the Distribution Transformers}

Low frequency signals, obviously including electricity at $60 \mathrm{~Hz}$ can easily pass through the distribution stepdown transformer. But high frequency signals, which for BPL are typically in the 2 to 80 mega hertz (MHz) range, are obstructed or severely attenuated by the transformer [6]. Although some of the signals get through, 
signal components can be so weak that they are difficult to detect or reconstruct. Accordingly, many BPL technology suppliers simply bypass the transformer.

\subsection{Potentially Harmful Radio Frequency Interference (RFI)}

Radio frequency interference has been one of the most serious potential obstacles to BPL. BPL systems have been shown to produce RF interference with nearby radio receivers, within up to 75 meters for mobile radios and 150 meters for fixed radios, according to the American Radio Relay League (ARRL). Also, various elements or structures in or near the powerlines readily become radiator or antennas at the high frequencies at which BPL data are transmitted. This presents a problem of interference with a variety of radio services.

\section{Overcoming Technical Challenges}

Conditioning the grid can improve power line performance by minimizing impedance mismatches, terminating stubs, filtering noise, etc. These options may deteriorate or diminish the advantages of power line grids. A better approach is to use modulation and coding schemes robust enough to work in the hostile power line channel environment. Currently, most BPL products use orthogonal frequency division multiplexing (OFDM) well known for its excellent robustness against channel distortions such as multipath and impulsive noise and for its good spectral efficiency, reasonable cost, and ability to avoid certain bands [2]. In BPL systems, multiple user modems are connected in a bus or star topology. Some type of medium access control (MAC) protocol must be implemented to provide communications through shared bandwidth on power lines. To provide the necessary quality of service (QoS) for applications that require bandwidth and performance guarantees, such as video streaming the carrier sensing multiple access/collision avoidance (CSMA/CA) protocol may be used.

\section{Current Status of BPL}

There are many examples of power line communication projects worldwide ranging from research and development (R\&D) projects to ISP commercial projects. Globally, the number of BPL players (electric utility companies, equipment manufacturers, investors etc.), field trials, and commercial deployments has been growing steadily in the last few years. In the US alone, there have been more than 39 trial deployments. The most vigorous testing and marketing are being done by USA communication companies like the Ambient, Amperion, Current Technologies, and Main.net [2]. BPL system of Ambient Corporation was deployed by Duke Energy over their systems in April 2008 [7]. In Spain, Endesa began its service in 2003 in Saragossa and Barcelona. In the same year, Iberdrola initiated its service in Madrid and Valencia [2]. Power plus Communications has started offering services in Germany, and Scottish Southern Electric in UK. In Romania, a BPL trial in the rural locality of Band \& Mures County offering phone and broadband internet access was introduced by the Ministry of Communications and Information Technology [7]. In Russian Federation, Electro-com has deployed widely BPL technology and offers internet access service in Moscow, Nizhny Novgorod, Ryazan, Kaluga and Rostovon-Don. InovaTech has been particularly active, with many successful trials in Australia, China, Hong Kong, Taiwan, Indonesia, Malaysia, and the Philippines. In Indonesia, KEJORA under their banner PLANET BROADBAND rolled out more than 300,000 homes enabled with Broadband over Powerlines by August 2010. In South Africa, Goal Technology Solutions (GTS) trailed the technology and is offering service in the suburbs of Pretoria and plans to extend it to other areas. In Ghana, Cactel Communications Ltd. successfully deployed an MV solution pilot project in the Graphic Communications Group in Accra in June, 2005 [7].

\section{Comparative Analysis of Broadband Access Technologies}

Now we will compare different access technologies in terms of speed, typical cost and network structure (Table 1). Figure 5 shows the differences of cost versus speed for several broadband access technologies. DSL and Satellite are not shown for higher data rates because the technologies don’t provide these data rates.

\section{Conclusion}

Even though the importance and direct socioeconomic impacts of access to broadband services are well understood, currently only 4 percent of the Earth's population has access to some type of broadband services, typically via DSL, cable modem or fibre [2]. BPL offers a new alternative means of providing high-speed Internet 
Table 1. Comparison of broadband access technologies.

\begin{tabular}{|c|c|c|c|c|}
\hline Access Technology & Speed & $\begin{array}{c}\text { Typical Cost per Month, } \\
2009\end{array}$ & Reach & Remarks \\
\hline $\begin{array}{l}\text { BPL_-broadband over } \\
\text { powerline, defined as } \\
\text { long-distance, high } \\
\text { speed transmission of } \\
\text { data over the power } \\
\text { delivery system. }\end{array}$ & $\begin{array}{l}\text { Commercial - up to } 3 \\
\text { Mbps } \\
\text { Residences - } 5 \text { Mbps } \\
\text { or higher }\end{array}$ & $\begin{array}{l}{ }^{* *} 1800 \mathrm{BDT} \text { to } 2500 \mathrm{BDT} \\
{[4]} \\
\text { Depending on speed and } \\
\text { features. }\end{array}$ & $\begin{array}{l}\text { BPL can be applied to } \\
\text { the ubiquitous electric } \\
\text { distribution network. }\end{array}$ & $\begin{array}{l}\text { Speeds same for upload } \\
\text { and download; Number } \\
\text { of users affects the } \\
\text { speed. }\end{array}$ \\
\hline $\begin{array}{l}\text { Cable-use of cable TV } \\
\text { provider's coaxial or } \\
\text { fibre-coaxial systems to } \\
\text { transmit broadband } \\
\text { signals. }\end{array}$ & $1 \mathrm{Mbps}$ to $3 \mathrm{Mbps}$ & $\begin{array}{l}{ }^{* *} 2000 \mathrm{BDT} \text { to } 3200 \mathrm{BDT} \\
{[4]}\end{array}$ & $\begin{array}{l}\text { Available where cable } \\
\text { has been installed so } \\
\text { some rural and suburban } \\
\text { locations may not have } \\
\text { access. }\end{array}$ & $\begin{array}{l}\text { The speed of the signal } \\
\text { varies by the number of } \\
\text { users on the } \\
\text { neighbourhood network } \\
\text { loop; it degrades with } \\
\text { high numbers of users. }\end{array}$ \\
\hline $\begin{array}{l}\text { DSL_use of existing } \\
\text { copper telephone wires } \\
\text { to transmit broadband } \\
\text { signal. }\end{array}$ & $1.5 \mathrm{Mbps}$ & $\begin{array}{l}{ }^{* *} 1500 \mathrm{BDT} \text { to } 2600 \mathrm{BDT} \\
{[4]}\end{array}$ & $\begin{array}{l}\text { In general, a residence } \\
\text { must be within about } \\
18,000 \text { feet of the DSL } \\
\text { central equipment } \\
\text { office. }\end{array}$ & $\begin{array}{l}\text { Not capable of } \\
\text { transmitting TV signals. }\end{array}$ \\
\hline $\begin{array}{l}\text { Fibre (FTTx)—use of } \\
\text { optical fibre lines to } \\
\text { home (FTTH) or } \\
\text { business (FTTB) to } \\
\text { deliver broadband } \\
\text { services. }\end{array}$ & 1 Mbps to $1 \mathrm{Gbps}$ & $\begin{array}{l}\text { For } 1 \text { Mbps link: } \\
1500 \text { BDT [8] } \\
\text { For } 1 \text { Gbps link: } \\
\text { Instalment: } \\
\text { 70,000 BDT [8] } \\
\text { Maintenance: } \\
\text { 5000 BDT [8] }\end{array}$ & $\begin{array}{l}\text { Fibre to the premises is } \\
\text { available in some } \\
\text { locations, but its } \\
\text { deployment has been } \\
\text { limited by high costs. }\end{array}$ & $\begin{array}{l}\text { Cost reductions enabled } \\
\text { by passive optical } \\
\text { networks (PON) and } \\
\text { advances in component } \\
\text { technology are expected } \\
\text { to bring costs down. } \\
\text { Some telecom } \\
\text { companies are already } \\
\text { installing Fibre. }\end{array}$ \\
\hline Satellite & $500 \mathrm{Kbps}$ & $\begin{array}{l}2600 \mathrm{BDT} \text { to } 5300 \mathrm{BDT} \\
\text { [9] }\end{array}$ & $\begin{array}{l}\text { Requires a clear view to } \\
\text { the south (in the } \\
\text { northern hemisphere). }\end{array}$ & $\begin{array}{l}\text { Trees and even heavy } \\
\text { rain may affect } \\
\text { reception on Internet } \\
\text { data. }\end{array}$ \\
\hline $\begin{array}{l}\text { WiMax-worldwide } \\
\text { interoperability for } \\
\text { microwave access, based } \\
\text { on a January 2003 IEEE } \\
\text { standard (802.16), } \\
\text { supports development. }\end{array}$ & Up to 75 - $100 \mathrm{Mbps}$ & $\begin{array}{l}\text { Modem: } \\
\text { 4000 BDT [10] } \\
\text { For } 512 \text { Kbps: } \\
\text { 2250 BDT [11] } \\
\text { For } 1 \text { Mbps: } \\
\text { 5250 BDT [11] } \\
\text { For 256 Kbps: } \\
\text { 1250 BDT [11] }\end{array}$ & $\begin{array}{l}\text { Has a range of about } 10 \\
-12 \text { kilo meters of a } \\
\text { single base station. } \\
\text { This technology has a } \\
\text { predicted point-to point } \\
\text { range of } 25 \text { miles or } \\
\text { more [8]. }\end{array}$ & $\begin{array}{l}\text { WiMax has recently } \\
\text { entered the market. It is } \\
\text { expected to reduce its } \\
\text { service charge as it } \\
\text { could catch a large } \\
\text { number of customers. }\end{array}$ \\
\hline
\end{tabular}

${ }^{* *}$ This cost is an approximate value based on International market and calibrated for Bangladeshi market.

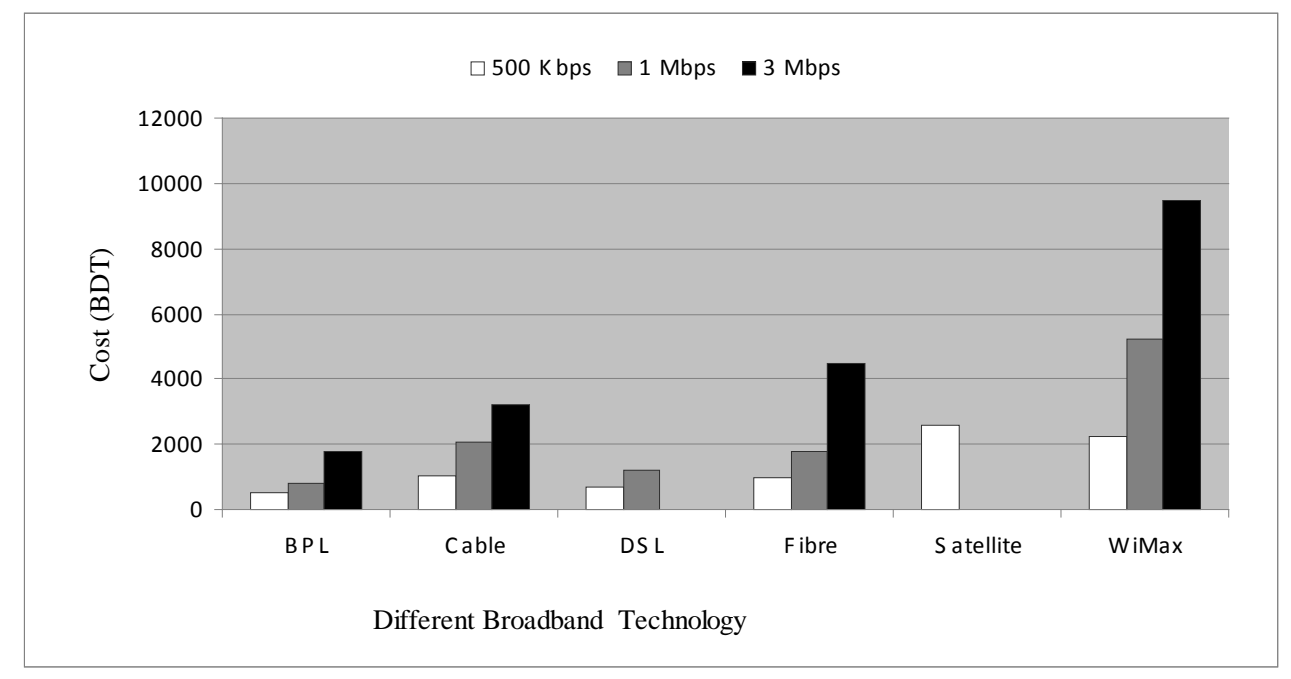

Figure 5. Comparative analysis between different broadband technologies. 
access, voice over Internet protocol (VoIP), video on demand (VOD) and other broadband services, using medium and low voltage lines to access homes and businesses. Because roughly 60 percent of Earth's inhabitants have access to power lines, BPL could play a significant role in bridging the existing digital divide. BPL could be an effective solution for providing broadband services in the regions, where a power substation has relatively small number of customers. But the success of BPL, like that of any new technology in its infancy, depends on strong theoretical results or successful field testing. It also depends greatly on the appropriate business models and deployment plans.

\section{References}

[1] Held, G. (2006) Understanding Broadband over Power Line. Auer Bach Publications, New York.

[2] Lushbaugh, L. and Safavian, R.S. (2007) Broadband over Power Line (BPL). Bechtel Telecommunications Technical Journal, 5, 1-16.

[3] The Ratepayer Advocate (2009) Broadband over Power Lines a White Paper. http://www.state.nj.us/rpa/BPLwhitepaper.pdf

[4] National Communications System (2009) Broadband over Power Lines. Technical Information Bulletin 07-1. http://www.w4clj.com/ncs-bpl.pdf

[5] Kutz, T.C. (2009) Broadband over Power Line: A New Technology for the Future. http://www.noblis.org/NewsPublications/Publications/TechnicalPublications/TelecommunicationsReview/Documents/ 08-Kutz-TR2005.pdf

[6] Gellings, C.W. and George, C. (2009) Broadband over Powerline 2004: Technology and Prospects. An EPRI White paper.

http://www.epri.com/search/Pages/results.aspx?k=Broadband\%20Over\%20Powerline\%202004:\%20Technology\%20an d\%20Prospects

[7] Wikipedia, the Free Encyclopedia (2009) List of Broadband over Power Line Deployments. http://en.wikipedia.org/wiki/List_of_broadband_over_power_line_deployments

[8] Internet Service Provider, Telnet Communication Limited, Dhaka, Bangladesh. http://www.telnet.com.bd/

[9] Internet Service Provider, Bangladesh Online Limited, Dhaka, Bangladesh. http://www.bol-online.com

[10] WiMax Service Provider, Banglalion Communication Ltd., Dhaka, Bangladesh. http://www.banglalion.com.bd

[11] WiMax Service Provider, Augere Bangladesh, Dhaka, Bangladesh. http://www.qubee.com.bd 
Scientific Research Publishing (SCIRP) is one of the largest Open Access journal publishers. It is currently publishing more than 200 open access, online, peer-reviewed journals covering a wide range of academic disciplines. SCIRP serves the worldwide academic communities and contributes to the progress and application of science with its publication.

Other selected journals from SCIRP are listed as below. Submit your manuscript to us via either submit@scirp.org or Online Submission Portal.
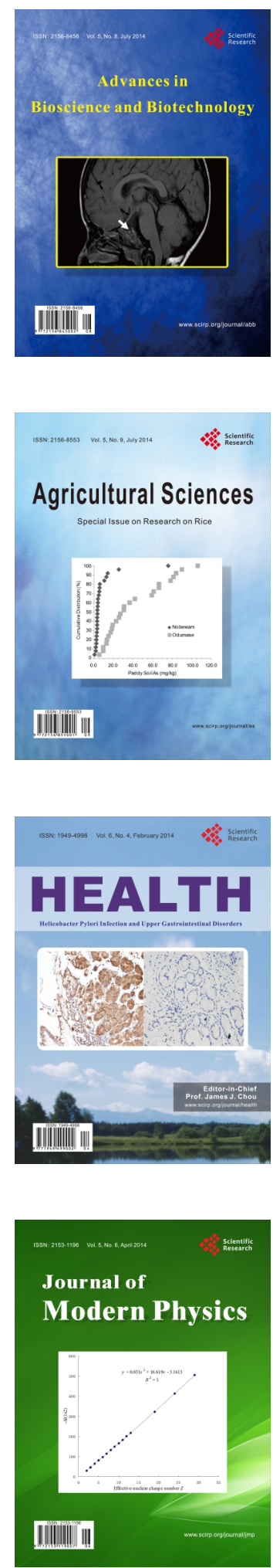
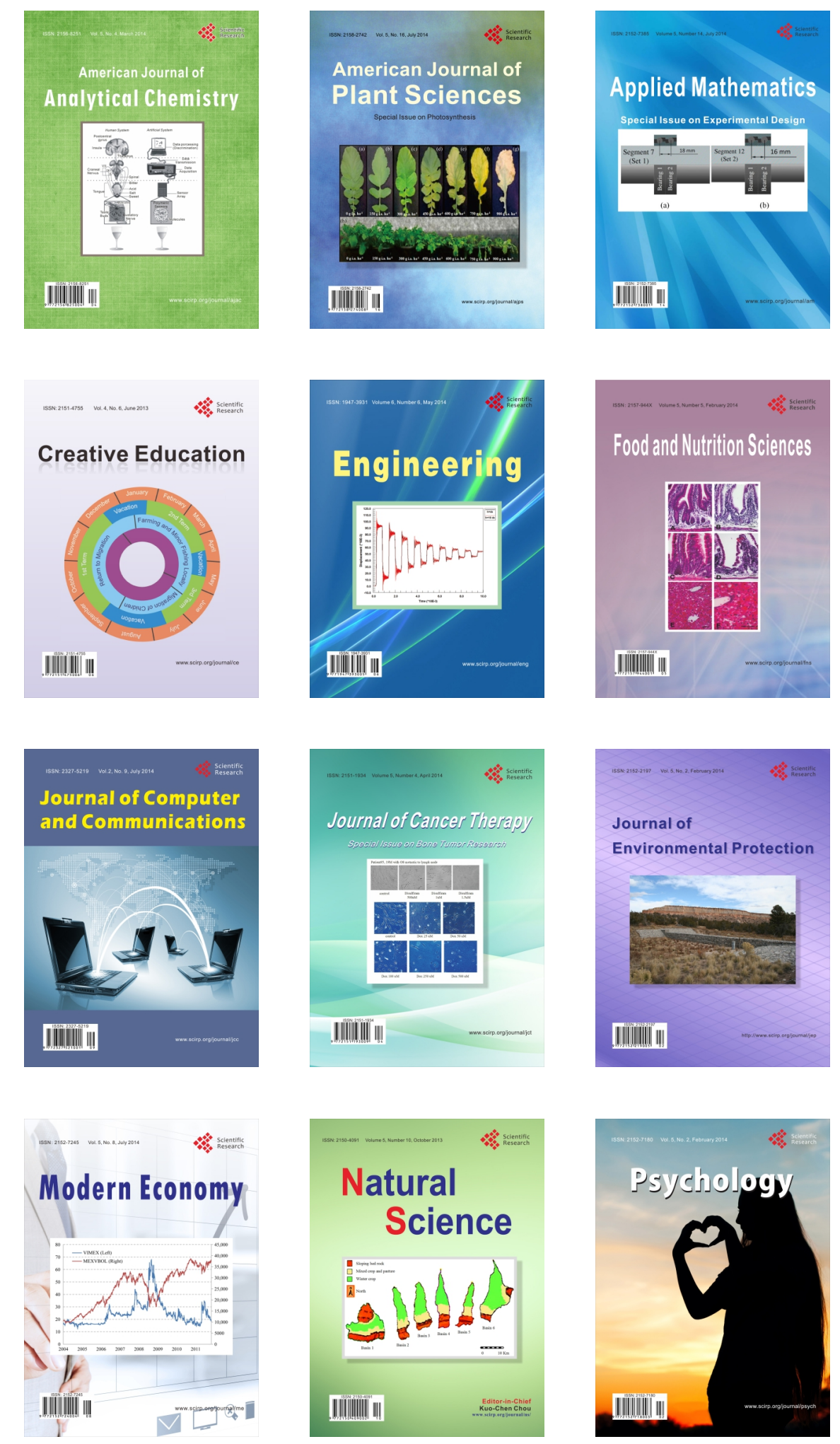